\title{
FORMAÇÃO DOCENTE NO CONTEXTO DA INTERNACIONALIZAÇÃO DAS POLÍTICAS EDUCACIONAIS: A TENSÃO ENTRE OS VALORES DA PROFISSÃO E OS VALORES DO MERCADO
}

\author{
TEACHER EDUCATION IN THE CONTEXT OF INTERNALIZATION OF \\ EDUCATIONAL POLICIES: THE TENSION BETWEEN THE VALUES OF THE \\ PROFESSION AND MARKET VALUES
}

\section{LA FORMACIÓN DEL PROFESORADO EN EL CONTEXTO DE LA INTERNACIONALIZACIÓN DE LAS POLÍTICAS EDUCATIVAS: LA TENSIÓN ENTRE LOS VALORES DE LA PROFESIÓN Y LOS VALORES DEL MERCADO}

Altair Alberto Fávero*

Evandro Consaltér*

\begin{abstract}
Resumo: A internacionalização das políticas educacionais tem acarretado um fenômeno antagônico entre duas formas de conceber o processo educativo, ocasionando uma tensão entre o valor da profissão e o valor do mercado. De um lado, sobrepõem-se as necessidades das escolas, dos alunos e da comunidade. A educação, nesses termos, é entendida de caráter comum, com acesso aberto e inclusão social, com ênfase sobre a atribuição de recursos àqueles com maiores necessidades de aprendizagem. Do outro lado, atendendo aos interesses de órgãos como FMI, OCDE e Banco Mundial, prioriza-se a performance individual das escolas e dos alunos, com mecanismos de seleção e exclusão, visando atrair clientes, atingir metas, com privilégio de recursos àqueles considerados mais aptos. Diante desse contexto, emergem de forma acentuada projetos de formação "facilitada", em curto prazo, de venda de pacotes formativos, de trabalhadores que atuam como freelance, como consultores em educação, agindo no intuito de potencializar resultados e qualificar indicadores externos, que funcionariam, em tese, como indicativos de qualidade. Além de acarretar a perda de sentido e de identidade da profissão, esse processo também pode representar prejuízos de ordem qualitativa e quantitativa à educação e às políticas de formação de professores.
\end{abstract}

Palavras-chave: Políticas educacionais. Internacionalização. Identidade e formação docente.

\begin{abstract}
The internationalization of educational policies has entailed an antagonistic phenomenon between two ways of conceiving the educational process, causing a tension between the value of the profession and the value of the market. On the one hand, overlap the needs of schools, students and the community. In these terms, education is understood as a common character with open access and social inclusion, with an emphasis on the allocation of resources to those with the greatest learning needs. On the other hand, in the interests of bodies such as the IMF, OECD and World Bank, the individual

\footnotetext{
* Pós-Doutor (Bolsista Capes) pela Universidad Autónoma del Estado de México (UAEMéx). Professor e pesquisador no Curso de Filosofia, no Mestrado e Doutorado em Educação da Universidade de Passo Fundo, UPF. E-mail: altairfavero@gmail.com

${ }^{* *}$ Mestre em Educação pela Universidade de Passo Fundo (UPF). Professor do Curso de Pedagogia da Faculdade da Associação Brasiliense de Educação, FABE, na cidade de Marau/RS. E-mail: evandroconsalter@gmail.com
} 
performance of schools and students is prioritized, with selection and exclusion mechanisms, aimed at attracting clients, achieving goals, and privileging resources to those considered more suitable. In this context, emerge sharply training projects "facilitated", in the short term of sales of training packages, of workers who act as freelancers, as consultants in education, acting in order to potentiate results and qualify external indicators, which would theoretically work as indicators of quality. Besides causing loss of meaning and identity of the profession, this process can also represent losses of qualitative and quantitative education and teacher training policies.

Keywords: Educational policies. Internationalization. Teacher identity and teacher education.

Resumen: La internacionalización de las políticas educativas ha provocado un fenómeno antagónico entre dos formas de concebir el proceso educativo, causando tensión entre el valor de la profesión y el valor de mercado. Por un lado, se superponen las necesidades de las escuelas, los estudiantes y la comunidad. La educación en estos términos, se entiende en el carácter común, con acceso abierto y la inclusión social, con énfasis en la asignación de recursos aquellos con mayor necesidades de aprendizaje. Por otra parte, teniendo en cuenta los intereses de organismos como el FMI, OCDE y el Banco Mundial, se prioriza la actuación individual de las escuelas y estudiantes, con mecanismos de selección y exclusión, con el objetivo de atraer clientes, alcanzar metas, con el privilegio de recursos aquellos que se consideren más aptos. Ante este contexto, emergen de forma acentuada proyectos de formación "facilitada" en corto plazo, de venta de paquetes de formación, de trabajadores que actúan como freelance, como consultores en educación, actuando con el fin potenciar los resultados y calificar los indicadores externos, que funcionaría en teoría, como indicativo de la calidad. Además de causar la pérdida de sentido y la identidad de la profesión, este proceso también puede representar pérdida del orden cualitativa y cuantitativa a la educación y las políticas de formación del profesorado.

Palabras claves: Políticas educativas. Internacionalización. Identidad y formación del profesorado.

\section{Introdução}

A internacionalização das políticas educacionais, através do financiamento competitivo e contratual da educação, com foco em resultados, tem acarretado um fenômeno antagônico entre duas formas de conceber o processo educativo, ocasionando uma tensão entre o valor da profissão e o valor do mercado. Dessa forma, apresentamos neste estudo uma abordagem analítica bibliográfica sobre esse fato, apontando os seus reflexos especificamente sobre as políticas de formação de professores.

Primeiramente, trataremos de abordar esse processo a partir do que Ball e Youdell (2007) definem como "valores da profissão". Ou seja, de uma educação pautada pelas características dos alunos e da comunidade, de caráter comum e de acesso aberto, com inclusão social e ênfase sobre a atribuição de recursos àqueles com maiores necessidades de aprendizagem. Essa forma de pensar a escola e a atividade docente também compreende a cooperação entre as escolas e os alunos, onde as avaliações de desempenho sejam pautadas pelas qualidades acadêmicas e sociais e a educação de todas as crianças é considerada intrinsicamente de valor igual.

Em seguida, fazendo o contraponto a essa forma de pensar a educação, debatemos o lado oposto desse processo dual, o qual Ball e Youdell (2007) definem como "valores do mercado”. Agora, os processos de cooperação entre alunos e escolas perdem espaço para a performance individual de ambos, pela diferenciação e hierarquia, acompanhadas de processos de seleção e exclusão, atendendo aos interesses de órgãos externos tais como FMI, OCDE e Banco Mundial. Nesse viés, 
prioriza-se a atribuição de recursos àqueles considerados mais aptos. Estabelecem-se processos de competição e as avaliações são restritas ao critério de mérito, com base na contribuição dos indicadores externos de desempenho e a educação das crianças é avaliada com base nos custos e resultados.

Diante desse contexto, onde impera a necessidade de atingir resultados satisfatórios e em curto prazo, emergem de forma acentuada projetos de formação "facilitada", de venda de pacotes formativos, de trabalhadores que atuam como freelance, como consultores em educação, agindo no intuito de potencializar resultados e qualificar indicadores externos, que funcionariam, em tese, como indicativos de qualidade. Esses eventos, típicos de um processo de mercantilização de eventos formativos, correspondem a uma concepção de manipulação, de implementação de cursos curtos e rápidos, de palestras e encontros esporádicos como alternativa para a consolidação de um maior grau de aptidão para atingir determinados resultados.

Assim, trataremos de abordar no decorrer deste estudo os reflexos desse tensionamento sobre o processo de formação de professores. Acreditamos que a organização das práticas formativas associada às condições de trabalho, aos termos e espécies dos contratos e salários dos professores, a natureza das atividades e a forma como vivem suas vidas profissionais podem influenciar na consolidação ou na verdadeira desprofissionalização. (AKKARI, 2011). Esse processo, além de acarretar a perda de sentido e de identidade da profissão docente, pode acarretar prejuízos de ordem quantitativa e qualitativa ao processo educativo.

\section{Formação docente no contexto dos valores da profissão}

A compreensão de uma profissão pautada por um ideal de caráter comum, que compreende a educação de todas as crianças intrinsicamente de valor igual, caracteriza o conjunto de valores que definem a profissão docente em seu sentido mais antagônico aos anseios do mercado, os quais abordaremos na próxima seção. No contexto dos valores da profissão, privilegia-se a atribuição de recursos àqueles com maiores necessidades de aprendizagem, pois, de acordo com Ball e Youdell (2007), o exercício docente deve ser agente mediador da cooperação entre as escolas, os alunos e a comunidade, com acesso aberto, promovendo a inclusão social.

Nesse sentido, Nóvoa (1992) considera que a profissão docente entendida como ferramenta para o exercício de uma educação de caráter comum, a partir das necessidades de alunos e comunidade, tem como pressuposto práticas de formação que tomem como referência as dimensões coletivas. Dessa forma, contribuiriam para a emancipação profissional e para a consolidação de uma profissão que é autônoma na produção dos seus saberes e dos seus valores.

Considerando esses fatores, Pimenta (2008) destaca a possibilidade da construção de uma identidade profissional do professor. Uma identidade que se constrói a partir da significação social da profissão e da constante revisão desses significados, os quais podem ser mutáveis com a passagem do tempo ou permanecerem consagrados como práticas culturalmente significativas.

Essa identidade está estreitamente ligada ao "eu” pessoal de cada professor, como sua história de vida, suas angustias, suas experiências, seus desejos e sua forma de ver o mundo fazem parte dessa construção. 
Decorrente dessas particularidades, Pimenta (2008) elenca três saberes da docência como elementos constitutivos da identidade profissional dos professores: a experiência, o conhecimento e os saberes pedagógicos. A mobilização desses três saberes seria responsável, segundo a autora, pela construção de uma identidade da profissão docente, pautada, como também apontam Ball e Youdell (2007), nos valores e na representação social da profissão.

Sobre os saberes da docência elencados por Pimenta (2008), quanto ao primeiro deles, ou seja, os saberes da experiência, considera que todos os professores, em um determinado período de suas vidas passaram pela escola como alunos e, dessa forma, guardam lembranças desses tempos em relação aos seus professores, seus colegas e a diferentes escolas. Além disso, outros, já tiveram a oportunidade de estarem nas salas de aula como professores em virtude de um magistério ou de um curso técnico que lhes concedeu a oportunidade de ministrarem determinados conteúdos específicos. Neste caso, o desafio dos cursos de formação inicial é, portanto, fazer com que esses profissionais construam sua própria identidade profissional e superem o olhar sobre a docência, sobre o ser professor e a escola do ponto de vista do ser aluno e passem a vislumbrar do ponto de vista de ser professor.

Esse desafio da formação inicial materializa-se, principalmente, no momento da inserção do professor iniciante no mercado de trabalho. A sua compreensão sobre os valores da profissão poderá definir, entre duas dimensões, por qual orientará o exercício da docência. Akkari (2011) define essas duas dimensões a partir da compreensão de que uma trata a inserção no mercado de trabalho como busca por uma profissão e a outra como fase de entrada na profissão docente ou primeira fase da carreira docente.
A primeira delas inicia no final da graduação e terminaria com a obtenção de um primeiro emprego estável ou permanente. A segunda dimensão se efetivaria, conforme as próprias palavras de Akkari (2011, p. 116), “[...] no momento em que o jovem professor aprende a dominar o seu trabalho, a descobrir os seus próprios recursos e limites, a construir uma bagagem de saberes e habilidades a partir da experiência da profissão docente.” Nesta segunda dimensão, diferentemente da anterior, a ênfase fica muito mais sobre a aprendizagem do trabalho e a formação a partir do trabalho do que sobre a procura por um primeiro emprego.

Retomando os saberes da profissão abordados por Pimenta (2008), a segunda categoria nominada pela autora diz respeito aos saberes do conhecimento. Estes fazem referência ao mundo de informações em que estudantes de graduação de cursos de licenciatura são submetidos. A dúvida que paira sobre os futuros profissionais é o que e como lidar exatamente com esse conhecimento. Em decorrência de uma formação inicial com falhas pedagógicas, Esteve (2004) considera que alguns modelos de formação têm criado uma identidade profissional falsa nos futuros professores. Esses profissionais chegam a se imaginar profissionalmente trabalhando como historiadores ou químicos, quando, na realidade, trabalharão profissionalmente como professores de história ou de química.

É dessa preocupação de uma formação pedagógica do profissional da educação que deriva a terceira categoria elencada por Pimenta (2008), que diz respeito exatamente aos saberes pedagógicos. Estes, segundo a autora, revelam a necessidade desses profissionais incorporarem à sua bagagem formativa não apenas conhecimentos específicos, mas também saberes pedagógicos e didáticos. Na história dos cursos de formação de professores, como já visto, esses saberes têm 
sido trabalhados de forma isolada e distinta. Na história da educação, sobressaem-se destaques sobre os saberes científicos e saberes técnicos, porém, ao passo que a escola configura-se como uma instituição não estática, assim como mudam as características sociais, o fazer pedagógico também deve ser ponto de análise e reflexão.

Diante deste contexto, Akkari (2011) vê que as políticas educacionais, cada vez mais preocupadas com essa fase de inserção do futuro profissional, acabam elaborando estratégias para identificar e suprir essas lacunas deixadas na formação inicial. Entre estas estratégias, o autor destaca a diminuição de carga horária, projetos de formação continuada e um acompanhamento pelos pares, por exemplo.

É também nesse sentido que Akkari (2011) considera que a formação inicial dos professores pode assumir formas muito diferenciadas quanto a sua duração, prioridades e lugar da prática. Assim, o autor aponta dois modelos que considera mais latentes em relação à organização da formação. O primeiro deles, intitulado de formação simultânea, compreenderia um foco disciplinar, didático, pedagógico e profissional. Já o segundo, denominado de formação sucessiva, teria o foco disciplinar na universidade e, posteriormente, o foco didático, profissional e pedagógico, ocorrendo simultaneamente com o já exercício da profissão.

Por sua vez, esse professor já inserido no mercado de trabalho também é capaz de produzir o seu próprio conhecimento, por meio da investigação da ação, da prática e do fazer cotidiano, em que se revelam as contingências, complexidades e problemas que devem ser enfrentados, abrindo espaço para a reflexão e a criatividade. Para Fávero e Tonieto (2010, p. 70), esse processo de construção é característico do professor prático-reflexivo, que vê nos momentos de formação, sejam eles cursos, palestras, pós-graduações, grupos de estudo, seminários e trabalhos em sala de aula, referenciais para compreender o agir pedagógico, uma vez que é da reflexão sobre a prática que brotam os elementos criativos da crítica e da mudança.

Nessa direção proposta por Fávero e Tonieto (2010), a constituição de uma identidade profissional de professores como profissional prático reflexivo e não como um técnico especializado, tanto na visão de Pimenta (2008), Nóvoa (1992) e Akkari (2011), configura-se como elemento fundamental para se alcançar uma melhor qualidade profissional a partir dos cursos de formação inicial. Dessa forma, os saberes do conhecimento constituiriam uma profissão pautada por valores da docência que contemplariam ao mesmo tempo os saberes disciplinares e pedagógicos, tendo em vista uma educação de caráter comum e a cooperação entre escolas, alunos e comunidades.

Essa concepção vai ao encontro do que Nóvoa (1992) defende como práticas de formação que tomam como referência as dimensões coletivas. Como já abordamos anteriormente, Nóvoa (1992) compreende que essa formação contribui para a emancipação profissional e para a consolidação de uma profissão que é autônoma na produção dos seus saberes e dos seus valores. Ao contrário, as práticas de formação continuada organizadas em torno dos professores de forma individual podem ser úteis sim para a aquisição de conhecimentos e de técnicas, porém, favorecem o isolamento, a individualidade e reforçam uma imagem de professores como transmissores de um saber produzido na exterioridade da profissão docente.

É nesse caminho da individualidade e da exterioridade da profissão que atua outro conjunto de valores, os valores do mercado, 
responsáveis pelo tensionamento com os valores da profissão, historicamente e socialmente constituídos, como ora exposto. É sobre essa segunda categoria que passaremos a analisar na próxima seção.

\section{Formação docente no contexto dos valores do mercado}

A formação de professores, inevitavelmente, tem sido afetada nos últimos anos pelo processo de internacionalização das políticas educacionais. Esse processo tem gerado novas formas de regulação dessas políticas e, consequentemente, atribuído novos valores sobre a profissão docente, como, por exemplo, e de forma muito acentuada, os valores do mercado.

Se antes - no contexto dos valores da profissão - a compreensão da docência era pautada por um ideal de caráter comum, com uma concepção de educação para todas as crianças intrinsicamente de valor igual, agora abre-se espaço para a performance individual das escolas e dos alunos, para processos de diferenciação e hierarquias, de canalização, seleção e exclusão. Além disso, a educação no contexto do mercado objetiva atrair clientes, ocasionais e regulares, com ênfase sobre a atribuição de recursos àqueles considerados mais aptos. As avaliações são restritas do mérito, com base na contribuição dos indicadores de desempenho e a educação das crianças é avaliada com base nos custos e resultados. (BALL; YOUDELL, 2007, p. 47).

Essa concepção de educação pautada em resultados e metas abre espaço para uma acentuada projeção de modelos de formação “facilitada”, de venda de pacotes formativos, de trabalhadores que atuam como freelance, como consultores em educação. Esses profissionais orientam sua prática no intuito de potencializar resultados e qualificar indicadores externos, que funcionariam, em tese, como indicativos de qualidade diante dos processos de internacionalização da educação.

Entendemos que esses processos são acentuados ou mediados pela privatização da educação, diante da incapacidade do estado acompanhar e atingir números e metas estipuladas pela internacionalização das políticas educacionais. Dessa forma, é importante a compreensão das diferentes formas em que a privatização desse setor pode apresentar-se. Conforme Akkari (2011), a privatização da educação pode ser parcial ou total. Geralmente aparece de forma camuflada, o que acaba gerando uma indefinição entre as fronteiras do público e do privado. $\mathrm{O}$ autor cita algumas formas de perpetração do setor privado sobre o público, destacando entre elas o patrocínio de escolas públicas pelo setor privado; utilização de livros didáticos ou softwares desenvolvidos pelo setor privado; taxas de matrículas nas escolas públicas e expansão de aulas particulares para estudantes de escolas públicas Akkari (2011, p. 54).

Esses indicativos apontados por Akkari (2011) interferem diretamente na forma de atuação do professor, e principalmente no seu processo formativo. Recorrendo a Ball e Youdell (2007), pode-se afirmar que a tendência da privatização modifica a forma como os professores são preparados, a natureza do desenvolvimento, os termos e as condições dos contratos e salários, a natureza das atividades cotidianas dos professores e a própria maneira como eles vivem suas vidas profissionais.

Diante desse novo contexto, Akkari (2011) considera que a redução de gastos com o ensino público e o aumento da pressão sobre os professores para prestarem conta de suas ações pedagógicas são exemplos dos impactos da internacionalização das políticas educacionais. Da obrigação de mostrar resultados e atingir metas, surge mais um efeito 
da internacionalização sobre os processos de formação de professores: a venda de pacotes formativos que atendem as necessidades dos docentes diante das demandas do mercado.

Esses pacotes vendem a ideia de habilitar os professores para atingir determinados resultados estipulados pela escola, pelo governo ou pelos órgãos reguladores internacionais. Geralmente, desconsideram a historicidade da escola, dos seus alunos e da própria trajetória profissional dos professores, uma vez que são orientados pelos valores do mercado e não pelos da profissão docente.

Para Bittencourt (2014, p. 250), nesse cenário, “[...] a relação pedagógica entre professor e aluno se converte em uma relação comercial, na qual o docente se encontra na obrigação de tal como um vendedor de conhecimento, a satisfazer todos os caprichos de seu cliente.” Dessa forma, o autor considera que o próprio processo de ensino flexibiliza-se e se torna cada vez menos exigente intelectualmente. Além disso, com atividades cognitivas cada vez mais superficiais, visa modelar o estudante para um mercado de trabalho que exige a supressão da identificação existencial com seu oficio.

Esse contexto narrado por Bittencourt (2014), conforme o próprio autor, coloca o professor numa perspectiva condicionada pelos interesses do mercado.

O professor se encontra cada vez mais acuado em suas atividades profissionais, tornando-se uma espécie de servidor incondicional dos desejos imbecilizantes de uma estrutura socioeconômica que identifica no sistema educacional apenas um veículo para legitimação dos interesses das classes detentoras do poder de consumo de bens materiais e de diplomas que permitam sua inserção facilitada no mercado de trabalho. (BITTENCOURT, 2014, p. 260).
A constante retórica de uma profissão docente voltada aos interesses do mercado, conforme já expomos, acentua o processo de venda de pacotes formativos que atendem as necessidades dos docentes diante dessa realidade. No entanto, há de se considerar que esses “produtos” nem sempre têm por princípio a formação. Fávero e Esquinsani (2011), após a análise de oito eventos educacionais realizados no estado do Rio Grande do Sul, observaram um exacerbado apelo mercantilista do processo de formação docente continuada e, também, um esvaziamento da teoria como suporte epistêmico na sua efetivação.

Diante da venda de pacotes formativos, materializados em "momentos de formação", Nóvoa (1992) considera também que a separação entre pesquisadores que oferecem sua produção e professores na condição de consumidores, pouco ou nada acrescentam na reflexão ou proposição de novas práticas de ensino. Para Nóvoa (1992), deve existir um espaço fundamental de negociação, de conversa, de diálogo que, na verdade, estaria construindo os elos de significação pretendidos. Sem essa prerrogativa, a formação isolada e descontextualizada se restringe a um modelo sistemático, desprovido de qualquer intenção humanizadora e transformadora da realidade social em que professores e alunos estão inseridos.

Esses modelos de formação e a adoção políticas centradas nos valores do mercado, geralmente apoiam-se na justificativa de que o mercado é um mecanismo para a oferta da educação mais eficaz, ágil e eficiente. Além disso, seria possuidor de um conjunto de valores morais positivos por si mesmo, como o esforço, a austeridade, a autoconfiança e a independência. Ball (2001) afirma que essa perspectiva deixa muito claro o mercado como uma força transformadora, que carrega e dissemina os seus próprios valores. 
Esse contexto atinge todos os atores do processo educativo, como famílias, crianças e professores, passando a exigir que a escola assuma novos tipos de preocupações extrínsecas e, por consequência, reconfigure e revalorize o significado da educação. Para Ball (2001, p. 108) o valor do mercado “[...] cria novas identidades e destrói a sociabilidade, encorajando o individualismo competitivo e o instrumentalismo. Os espaços nos quais são possíveis a reflexão e o diálogo sobre os valores são eliminados.”

Esse modelo, típico das economias de mercado livre, sustenta os valores do mercado a partir da premissa de que a competição é um evento natural da condição humana. Todavia, Ball (2001) alerta para os prejuízos que essa visão pode acarretar a vida escolar dos estudantes, uma vez que o sistema coloca como prioridade indicadores como os custos e não os interesses e necessidades dos alunos.

Creio que "instituições de mercado em vez de proverem as estruturas para inclinações naturais, na verdade produzem as condições nas quais a mentalidade pode florescer". No contexto deste novo ambiente moral, o/a estudante é cada vez mais mercantilizado. Cada estudante é posicionado/a e avaliado/a de uma forma diferente no mercado educacional, ou seja, o processo de competição institucional no mercado apela a uma "economia do valor do/a estudante”. Nos sistemas onde o recrutamento está diretamente relacionado ao financiamento e indicadores do desempenho são publicados como "informações do mercado", os “custos" educacionais e da reputação do/a estudante, e não os seus interesses e necessidades, passam a ser centrais na resposta dos "produtores" aos que exercem o seu direito de escolha. Isto ocorre também onde a exclusividade é um aspecto central na posição do mercado escolar. (BALL, 2001, p. 108).
Pensar a formação de professores a partir dos valores do mercado requer a compreensão de que, nesse contexto, as dinâmicas de escolha e da competição acabam por produzir um novo "currículo oculto”. Para Ball (2001, p. 108), “[...] o conceito e o propósito da educação, a natureza das relações sociais da escolarização, as relações professor/estudante, professor/pais, estudante/estudante são todas desafiadas pelas forças e micro práticas do mercado."

Se antes, a profissão docente era pautada por um conjunto de valores éticos historicamente constituídos acerca da atividade, agora, conforme Akkari (2011) a docência é vigiada pelo olhar atendo de investidores que veem a escola como o grande mercado do século XXI. Essa nova visão, como analisamos, vem perpetrando cada vez mais suas diretrizes sobre a função da escola e do professor. Diante desse contexto, Akkari (2011) considera que a educação pública se encontra na interseção de dois direitos legítimos, mas não necessariamente conciliáveis. Um, que dá o direito de toda a sociedade democrática prover às futuras gerações conhecimentos e valores comuns. O outro, que prevê o direito das famílias decidirem sobre quais influências seus filhos serão expostos.

Porém, esses dois direitos tornam-se inconciliáveis quando o papel do estado se resigna frente às investidas do mercado em situações em que as condições socioeconômicas da população são realidades muito discrepantes, realidade de países emergentes como o Brasil. Nesse caso, a tendência mercadológica da educação pode acarretar sérios problemas se não acompanhada de uma força reguladora capaz de garantir o acesso a uma educação de qualidade a toda população. Ao invés de configurar-se como sinônimo de competição e desenvolvimento, retórica defendida pelos empresários da educação, contribui para o aumento e afirmação das desigualdades sociais. 
Com um estado reduzido e uma educação descentralizada, ignoram-se as características regionais em detrimento dos interesses corporativos das empresas da educação. Por sua vez, com uma insuficiência de recursos, estados e municípios não conseguem assegurar o seu pleno papel na educação. (AKKARI, 2011, p.44). Dessa forma, entende-se que os valores do mercado orientam a formação de professores para atingirem metas, resultados e objetivos, geralmente postos por organismos multinacionais e inobservantes das peculiaridades locais e das verdadeiras necessidades da população. A educação e a docência tornam-se então não mais pautadas pela sua historicidade e valores da profissão, mas sim pelas normas e arranjos econômicos, políticos e comerciais firmados pelos seus novos gestores.

\section{Considerações finais}

No contexto da internacionalização das políticas educativas, sob os efeitos da globalização e da privatização da educação, podemos afirmar que os valores da profissão enfrentam um acentuado enfraquecimento em detrimento dos valores do mercado. Dessa forma, as estruturas emergentes de gestão e regulação da educação, que enfatizam as políticas de auditoria, regulação e unidades de prestação de serviços, refletem o papel de controle à distância de um estado mínimo. Conforme Ball, o papel deste estado é de "[...] instituir um novo quadro de incentivos, eliminar constrangimentos desnecessários e provocar uma transformação radical na cultura e no desempenho.” (BALL, 2001, p. 112).

Essa realidade, conforme o próprio autor argumenta, mais do que implicar nos valores da profissão docente, lança seus efeitos sobre as próprias organizações das práticas formativas associadas às condições de trabalho, aos termos e condições dos contratos e salários dos professores. Para Akkari (2011), a necessidade de prestação de contas, de atingir metas a qualquer custo e de apresentar resultados em forma de indicativos, pode influenciar na consolidação ou na verdadeira desprofissionalização docente.

Por outro lado, em era globalizada é impossível ignorar as novas demandas sociais, econômicas, políticas e educacionais, por exemplo. Diante desse contexto da internacionalização, a descentralização da educação com a perpetração do setor privado sobre o público torna-se uma consequência comum desse processo, pautada em maior ou menor grau. Buscar a equidade seria o caminho mais adequado para evitar a radicalização apenas em favor dos valores do mercado ou dos valores da profissão.

Diante desse contexto, Akkari (2011) cita o exemplo de duas funções da educação que poderiam ser facilmente descentralizadas e outras duas que deveriam permanecer, de preferencia, centralizadas. As duas primeiras dizem respeito à adaptação das práticas de ensino às condições locais e às parcerias entre escolas e famílias. As duas que deveriam permanecer centralizadas compreendem a garantia de financiamento equitativo entre as regiões de um país visando suas demandas locais da educação e a outra abarcando o controle da qualidade da educação. Essa qualidade compreendida quanto à formação dos professores, aquisições dos alunos e aos padrões de saúde e segurança dos mesmos.

Enfrentar esses desafios seria o caminho mais adequado para a escola e a docência não fecharem os olhos às novas tendências globais e, ao mesmo tempo, garantirem a qualidade dos processos educativos, preservando os aspectos centrais da identidade docente, socialmente e historicamente construídos. Reafirmamos, dessa forma, a definição de Nóvoa (1992), acreditando que assim a 
profissão docente poderia ser entendida como ferramenta para o exercício de uma educação de caráter comum, a partir das necessidades de alunos e comunidade, consolidando-se como uma profissão autônoma na produção dos seus saberes e dos seus valores.

Uma educação pautada apenas pelos valores do mercado, como analisamos, coloca em primeiro plano resultados e metas, abrindo espaço para uma acentuada projeção de modelos de formação "facilitada”, de venda de pacotes formativos, com os trabalhadores atuando como freelance. Concordamos com Bittencourt (2014, p. 250), ao considerar que nessa realidade mercadológica da educação, “[...] a relação pedagógica entre professor e aluno se converte em uma relação comercial, na qual o docente se encontra na obrigação de tal como um vendedor de conhecimento, a satisfazer todos os caprichos de seu cliente.”

Por fim, esse fenômeno antagônico entre essas duas formas de conceber o processo educativo, acarretado, sobretudo, pela internacionalização das políticas educacionais, mais do que provocar a tensão entre os valores da profissão e os valores do mercado, tem ressignificado a essência da formação docente. Pensar em políticas que possam conciliar os valores da profissão e os valores do mercado e assegurar um equilíbrio entre o público e o privado é o desafio das políticas educacionais para se evitar a consolidação do que Akkari (2011) chama de "desprofissionalização docente” e, assim, impedir perdas de ordem qualitativa e quantitativa ao processo educativo, prenunciadas por essas duas formas antagônicas de conceber o processo formativo dos profissionais da educação.

\section{Referências}

AKKARI, A. Internacionalização das políticas educacionais: transformações e desafios. Petrópolis: Vozes, 2011.
BALL, S. J. Diretrizes políticas globais e relações políticas locais em educação. Currículo sem Fronteiras, [s.l.], v. 1, n. 2, p. 99-116, jul./dez. 2001.

BALL, S. J.; YOUDELL, D. Privatización encubierta en la educación pública. In: INTERNACIONAL DE LAEDUCACIÓN CONGRESO MUNDIAL, 5., 2007, Berlim. Informe preliminar... Londres: Instituto de Educación, Universidad de Londres, 2007. Disponível em: <https://www.joanmayans. com/privatizacion_encubierta_de_la_ educacion_publica.pdf $>$.

BITTENCOURT, R. N. A mercantilização educacional e a ideologia do ensino espetacular. Revista Lugar Comum, Rio de Janeiro, n. 43, p. 249-624, maio/ago. 2014.

ESTEVE, J. M. A terceira revolução educacional: a educação na sociedade do conhecimento. São Paulo: Moderna, 2004.

FÁVERO, A. A.; ESQUINSANI, R. Me ame, me abrace, me acolha! Saberes docentes e políticas de formação continuada. Revista Contrapontos, Itajaí, v. 11, n. 1, p. 6-13, jan./abr. 2011.

FÁVERO, A. A.; TONIETO, C. Educar o educador: reflexões sobre a formação docente. Campinas: Mercado de Letras, 2010.

NÓVOA, A. Formação de professores e profissão docente. In: __ Os professores e sua formação. Lisboa: Instituto de Inovação Educacional, 1992. p. 139-158.

PIMENTA, S. G. Formação de professores: identidade e saberes da docência. In:

(Org.). Saberes pedagógicos e atividade docente. São Paulo: Cortez, 2008. p. 15-32. 